\title{
Unfixing the Concept of Illustration: Its Historiographical Ambivalence and Analytical Potential
}

Sonya Petersson

\section{Abstract}

Intermediality enters this study through the concept of illustration. The study's twofold objective is to analyse the concept of illustration historiographically and operationally. The leading questions concern how the concept of illustration has been verbalized and negotiated in both textual and pictorial media, and how it can be further used as an analytical tool in studying illustrations. On the one hand, "illustration" is examined as a genre of pictures, whose characteristic trait is the combined mediality of textual and pictorial elements being both materially present in the same object. On the other hand, it is examined as a genre of pictures also bearing upon/being modelled by past and present meta concepts, such as "illustration." The study makes two claims: one historiographical and one operational. The first is underbuilt by juxtaposing a concept of illustration derived from analysis of historiographic texts with a pictorial instance of the genre of illustration. Here, the outcome of analysis is to stress the historiographic concept of illustration as marked by the ambivalence of conflicting hierarchies and values. The second claim is conditioned by allowing the pictorial example to confront its meta concept. Here, the outcome of analysis is to demonstrate how the two functions of illustrated and illustrating are unfixed from their conventional ties to a textual source and pictorial target. Rather, the insight of study is that the functions of illustrated and illustrating are mutually reversible.

How to cite this book chapter:

Petersson, Sonya. "Unfixing the Concept of Illustration: Its Historiographical Ambivalence and Analytical Potential." In The Power of the In-Between: Intermediality as a Tool for Aesthetic Analysis and Critical Reflection, edited by Sonya Petersson, Christer Johansson, Magdalena Holdar, and Sara Callahan, 32I-347. Stockholm: Stockholm University Press, 20I8. DOI: https://doi.org/ıo.I6993/baq.m. License: CC-BY. 
The "same" object could through the serial course of an analysis occupy them both.

In lexical entries "illustration" is generally made synonymous with the function of making clear, evident, and lucid—an abstract definition also generally concretized with the example of a picture clarifying a textual source. The standard lexical entry thus touches upon two core aspects of the concept of illustration. Firstly, its characterization falls within the broad scope of intermedial terminology, since it concerns relations between textual and pictorial media. ${ }^{\mathrm{r}}$ Secondly, it makes the assumption that the relations between the media involved are asymmetric. The illustration is conventionally understood as conditioned by the object being illustrated. With this said, it is of foremost importance and the very impetus of the present study, to recognize that the lexical definition does not need to correspond neatly to other possible definitions or give an apt description of the pictorial genre sharing its name.

The study's twofold objective is to analyse the concept of illustration historiographically and operationally. On the one hand, this includes disassociating the concept of illustration from a set of powerful assumptions within the post-eighteenth-century field of illustration studies. The leading question here concerns how the concept of illustration implicitly and explicitly has been verbalized and negotiated-in both textual and pictorial media. To meet this end, the study juxtaposes definitions of illustration with an actual illustration, a picture taken from the nineteenthcentury illustrated press, which is asked to be self-referential or demanded to illustrate itself as an instance of its own media genre. On the other hand, I also aim to let the analysis of the concept of

I In the terminology elaborated by Irina O. Rajewsky, "illustration" both falls within intermediality in the "broad sense" of an umbrella term for relations between different media or rather phenomena taking place between media, and intermediality in the "narrower sense" of "media combinations," where text and picture are both materially present in the same media product. Irina O. Rajewsky, "Intermediality, Intertextuality, and Remediation: A Literary Perspective on Intermediality," Intermediality: History and Theory of the Arts, Literature and Technologies, no. 6 (2005): 46, 5I-53. 
illustration serve as a case for discussing how illustrations illustrate, which "texts" they illustrate, and how the objects involved confront and/or bear upon each other.

If the first aspect has historiographic and media-historical relevance, the second has analytical relevance also for studies without an interest in the pictorial genre of illustration. Behind this claim lies the insight that once any picture-belonging to the genre of illustration or not-is made into an object of analysis and verbalized in the written representation of a study, it also comes to illustrate the arguments being made, whatever else it has been understood to illustrate in its different sites of reception, past and present. The reason to engage with the particular genre of illustration is that it especially presses the case, in being a type of picture conventionally expected to illustrate-but how, exactly? Neither the particular time and media of the later nineteenth century are accidental, but motivated by the period's extraordinary proliferation of illustrations in new media of pictorial reproduction (in xylography, lithography, steel print, autotype, phototype to name but a few), which in its turn were related to a corresponding proliferation of words on illustration. ${ }^{2}$ The later part of the nineteenth century and its illustrated print media are decisive in the media history of the genre and the concept's modern historiography.

In other words, there has, since the nineteenth century, existed a corpus of writings that can be named illustration studies, ${ }^{3}$ or a discourse that provides a metalanguage on the pictorial genre

${ }^{2}$ For the production, publishing, and aesthetics of the genre of illustration in the nineteenth century, see, e.g., Andrea Korda, Printing and Painting the News in Victorian London: The Graphic and Social Realism (Burlington: Ashgate, 2015); Keri Yousif, Balzac, Grandville, and the Rise of Book Illustration (Burlington: Ashgate, 2012); Lorraine Janzen Kooistra, Poetry, Pictures, and Popular Publishing: The Illustrated Gift Book and Victorian Visual Culture I855-I875 (Athens: Ohio University Press, 20I I); Gerard Curtis, Visual Words: Art and the Material Book in Victorian England (Aldershot: Ashgate, 2002).

3 This naming is actually at odds with the self-proclamation of the field in the launching number of Journal of Illustration Studies, cf. "Editorial," Journal of Illustration Studies (December 2007), accessed August I8, 2015 , http://jois.uia.no/articles.php? article $=42$. 
of illustration, which in the following will be exemplified by Henry Blackburn's The Art of Illustration (I896 [I894]) and Walter Crane's Of the Decorative Illustration of Books Old and New (I 896). ${ }^{4}$ This is a field characterized by taking the illustration as an object of study to be discussed and theorized in its own right, including the selection of contemporary and historical examples and the delimitation of its "proper" qualities. What I above called "powerful assumptions" is to be found in the discourse of illustration studies and can-as a tentative start-be formulated as three normative criteria (henceforth called the conventional concept of illustration), that have had currency in the historiography of illustration studies in the nineteenth and the twentieth centuries: I) That the illustration should follow a textual source and that the paradigmatic case of the latter is delimited to the contents of a literary work; 2) That the illustration should illustrate "significant" aspects of the text as intended by the author; 3 ) That it is relevant to distinguish between artistic illustrations belonging to major literary genres like poetry and novels and non-artistic illustrations in other texts. ${ }^{5}$ These criteria have, not surprisingly, more recently been both contested and problematized. ${ }^{6}$ And if so, why are they relevant for the present study? It has to be stressed that my intention is not to take issue with what they are "saying."

${ }^{4}$ Henry Blackburn, The Art of Illustration (London, I 896 [1894]); Walter Crane, Of the Decorative Illustration of Books Old and New (London, I896).

5 See for example David Bland, A History of Book Illustration: The Illuminated Manuscript and the Printed Book (London: Faber and Faber Limited, 1958), I7-I9; Edward Hodnett, Image \& Text: Studies in the Illustration of English Literature (London: Scolar Press, I982), I-24 and esp. I3, from where the quotation is drawn.

${ }^{6}$ An older example is Meyer Schapiro, Words and Pictures: On the Literal and the Symbolic in the Illustration of a Text (The Hague: De Gruyer Mouton, I973) and a more recent is Hans Lund, Mötesplatser: Ord och bild $i$ samverkan (Lund: Intermedia Studies Press, 2013), 57-69. Lund offers the concept of "antiphonic" illustration for pictures that add to rather than in any direct way "translates" the textual source, or, as Lund describes it, continues the production of meaning where the text pauses. Lund's concept can further be compared with what Roland Barthes calls the "function of relay" and contrasts to textual "anchorage" in Image Music Text, trans. Stephen Heat (London: Fontana, I977), 38-4I. 
As obsolete today, it would miss the point. By enumerating them as normative clauses, I wish, on the one hand, to note the defining force that historiographically has been assigned to them, and, on the other, provide for readings of nineteenth-century texts that seek to unfix the already established convention from within its own discourse. This ambition involves reading strategies that are not so much seeking for deliberate propositions as for tensions and inconsistencies within them. Consequently, the conventional concept of illustration is not brought into the study as an object of analysis, but more as a condition.

The study builds on an operational definition of illustration that both takes account of and moves beyond its existence as a combined medium. The latter concerns the illustration's appearance in a conventionally text-based medium like a book or a magazine, where text and picture are present in their own materiality and approached as interrelated and meaning productive. ${ }^{7}$ Especially characteristic for the nineteenth-century illustrated press is not only the juxtaposition of pictures with whole blocks of texts but likewise with captions, titles, and inscriptions.

In addition to the combined media-approach, two further aspects are conditioning. The first relies on W. J. T. Mitchell's "imagetext," which is a concept of media hybridity. ${ }^{8}$ Even without captions etc., illustrations are never purely pictorial. Besides the often-recognized narrative aspects of motifs, they are also subject to encounter the words of a past or present metalanguage, or concepts like, for example, "illustration.” The crucial task is, however, to understand how various textual elements enter the pictorial genre and how the latter resists or accommodates them: Is it by titles and inscriptions? By an imposed metalanguage? By the content of the motif? My aim to use this study as a case for examining the analytical potential of the concept of illustration (as opera-

7 Rajewsky, "Intermediality, Intertextuality, and Remediation," 52.

8 W. J. T. Mitchell, Picture Theory: Essays on Verbal and Visual Representation (Chicago: University of Chicago Press, I994), 89, 95-99. See also W. J. T. Mitchell, Image Science: Iconology, Visual Culture, and Media Aesthetics (Chicago: University of Chicago Press, 201 5), 38-47, where the previous concepts of "imagetext," "image-text," and "image/ text" are further elaborated and fused into "imageXtext." 
tionally defined here) also calls for a preliminary account of what it means to say that something illustrates something else. The answer involves the relations between the positions of "illustrated" and "illustrating" and is implied in the dual option of "resists or accommodates" above. It is a point of departure comparable to what Mieke Bal argues for when she describes "images as texts" in the sense of semiotic entities with "referential recourse to words," and the ability to propose a "counter reading" to those words they in the first instance were "read" in the light of. 9 Following Bal, I understand the possible resistance of the illustrating object as entailing an analytical change of positions, or that the object previously used as illustrating is turned into the object illustrated the moment it is allowed to give rise to a "counter reading." " as much as possible, I will avoid the terms illustrating and illustrated, especially since the latter's passive form does not match the activity of providing the light on and possibly give rise to changes in a juxtaposed counterpart.

The first aspect of my operational definition thus regards the various ways in which illustrations and words intersect. The second aspect is a special case of the metalanguage included in the first, namely the concept of "new media," which I draw partly from Lisa Gitelman and partly from Bolter and Grusin. ${ }^{\text {II }}$ This perspective recognizes the genre of illustration within a cultural continuum of, and with referential relation to, other old and new media genres, and most importantly the new media of pictorial reproduction mentioned above. The "newness" of illustration

9 Mieke Bal, Reading "Rembrandt": Beyond the Word-Image Opposition (Cambridge: Cambridge University Press, I991), 35-39.

to Cf. the reversible and mutually re-modelling positions of (theoretical) concept and object in Mieke Bal, Travelling Concepts in the Humanities: A Rough Guide (Toronto: University of Toronto Press, 2002), 42-45, 6I.

in Lisa Gitelman, Always Already New: Media, History, and the Data of Culture (Cambridge: MIT Press, 2006), I-22; Lisa Gitelman and Geoffrey B. Pingree, eds., New Media, I740-I9I5 (Cambridge: MIT Press, 2003), xi-xxii; Jay David Bolter and Richard Grusin, Remediation: Understanding New Media (Cambridge: MIT Press, I999), see note 37 for further comments on my use of Bolter and Grusin's theory. 
in the particular case of the nineteenth-century illustrated press should however be separated both from its containing media (the magazine) and the combination of text and picture, which of course has a long history. Rather, it is the pictorial surface (not the surface of the page) that can be assigned the status of new media, building on the assumption that the visibility of the surface is due to media novelty or the reverse of media being so naturalized by age and habit that it has turned into a transparent package of content.

The study will unfold like this: In the first section I will deal with the concept of illustration as a historiographic entity and offer readings of Crane's and Blackburn's aforementioned texts. The overarching concern is to end up with a concept to bring to the next section, where it will confront an illustration taken from the Swedish nineteenth-century magazine Ny Illustrerad Tidning. The concept that is brought on is not a definition of the lexical kind. It is not even a concept of illustration, but a concept expressing what I will argue is a trait of the modern concept of illustration historiographically conceived, or a sort of tension. The latter is thus, together with some other meta concepts, made into a parameter for the illustration in the second section to further negotiate. In the course of analysis, I will have transferred a concept abstracted from historiographic readings to a picture representing the genre of illustration, and then, in reverse direction, bring qualities from the illustration to counter the concept. The overarching move is thereby more diachronic and transmedial than is suggested by the synchrony of the combined media approach. ${ }^{\mathrm{I} 2}$ Lastly and in conclusion, I will reflect on the concept of illustration as an analytical tool.

${ }^{12}$ About the division of the field of intermedia studies according to the parameters of synchronic and diachronic approaches and their function as analytical perspectives, see Lars Elleström, Media Transformation: The Transfer of Media Characteristics Among Media (Basingstoke: Palgrave Macmillan, 20I4), 3-4, 7 . 


\section{The Ambivalence of the Modern Concept of Illustration}

On the face of it, the definition of illustration offered by Henry Blackburn in The Art of Illustration relies on a double demand and a straightforward hierarchy:

The first object of an illustration, the principal part, is obviously, to illustrate and to elucidate the text-a matter often lost sight of. The second is to be artistic, and includes works of the imagination, decoration, ornament, style. ${ }^{\mathrm{I} 3}$

The first demand places the illustration in the position of a follower, in the normative sense that it should be led by something already present in "the text," which is also underlined by the subordinate clause criticizing much of the illustrated work of the present. ${ }^{\text {I4 }}$ Within the field of illustration studies, the first demand belongs to a model of definition that is production and author centred. In two well referred-to studies, David Bland and Edward Hodnett both emphasize the dependent role of the illustrative picture. In Bland, the dependence is measured against the relative autonomy of the text as the product of the author and the medium that comes first in the order of production. ${ }^{15}$ In Hodnett, it is assumed that " $[t]$ he best illustrators have the ability to understand the author's intention and to imagine what legitimately can be visualized beyond the words he[!] has used." ${ }^{16}$ From the historiographic point of view, it is therefore easy to detect the same hierarchy in Blackburn's definition. But of greater importance is that it is actually paired with an opposite tendency that renders the dependent position of the

${ }^{2} 3$ Blackburn, Art of Illustration, I 5 . Italics in the original.

${ }^{14}$ The first demand has also been noted as well-rehearsed in the literary criticism of the time, where illustrations were judged after how well they adhered to the intentions of the author or qualities first to be found in the literary work. This is exactly Nicholas Frankel's point when he contrasts the concept of illustration in the contemporary reception of the illustrator Aubrey Beardsley with an oppositional concept derived from Beardsley's drawings. Nicholas Frankel, Masking the Text: Essays on Literature of Mediation in the I890s (High Wycombe: The Rivendale Press, 2009), I 54-I 57, I60, I 80.

I5 Bland, History of Book Illustration, I9.

I6 Hodnett, Image \& Text, I7. 
illustration more complicated. At the same time as the illustration is described as a follower, it is demanded to "elucidate" or expose something that is deviant from its textual source, which is also echoing in the duality signaled by Hodnett's "beyond." Later on, when Blackburn makes a retrospective outlook to the "very earliest days of book illustration," he makes the comment that then

[t]he illustration was an illustration in the true sense of the word. It interpreted something to the reader that words were incapable of doing $[\ldots]{ }^{17}$

Although the objects referred to are particular historical examples, the statement is principal. It makes claims for what a "true" illustration does, which is to bring something new to the text that the words could not by themselves bring forth, and which depends on the mediation of "the reader." In other words, the conventional concept of illustration as a follower that is only allowed to reproduce what is already in the text, is simultaneously paralleled by a notion of illustration as additional to the text. This doubleness makes the first demand of the definition less straightforward than its propositional content suggests.

These two, both complementary and inconsistent, notions of illustration are connected by supplementary logic the way Derrida has explained the "supplement" as an exterior addition with the ambiguous function of being both superfluous (additional, exterior, extra) and necessary. The supplement adds to something that is supposed to be complete in itself. But as soon as the supplement is called in, that plenitude is threatened, or, as soon as the supplement is needed, it is reached out for to compensate for what Derrida calls an "anterior default" in the supposedly self-sufficient entity represented by the supplement. ${ }^{.8}$ This supplementary function is further encountered when the concept of the "shorthand of pictorial art" is introduced in Blackburn's text. The latter designates the communicative advantages of the genre of

${ }_{17}$ Blackburn, Art of Illustration, I 84 .

${ }^{18}$ Jacques Derrida, Of Grammatology, trans. Gayatri Chakravorty Spivak (Baltimore: Johns Hopkins University Press, I997 [I967]), I4I-I64, quote I 45 . 
illustration compared to what is described as its textual other. ${ }^{19}$ When the illustration - the follower-adds to its textual source, it is argued to do so in order to compensate for a deficiency in the textual medium that is also and paradoxically asserted to take the lead and supposed to be sufficient by itself (since the illustration should follow it or make no addition to it). The lack or deficiency the illustration is called in to "heal" is repeatedly described as the textual burden of un-perspicuity or its cumbersomeness, compared to the instantaneousness of pictorial representation. This is Blackburn's very point in enthusiastically promoting the "shorthand of pictorial art" and its ability to expose a piece of information by pictorial means-information that was not to be gained from the text that was expected to transmit it in the first place. ${ }^{20}$ Taken as information, the illustration is aimed at transmitting knowledge or a "content" that is not materially present. It is thereby assigned the task of working in the service of the words that the written text failed to bring forth, which is again an endorsement of the hierarchy of the first demand. But by the illustration's pictorial means, it serves as a necessary substitute to the deficient realization of meaning in writing. With the aid of the "shorthand of pictorial art," Blackburn assures that "our complicated language [will] be rescued from many obscurities," ${ }^{21}$ just as well as it will minimize the risk of misinterpretation or of conjuring up the "wrong" mental image. ${ }^{22}$

Another feature of the concept of illustration in Blackburn's treatise is that it is repeatedly used in conjunction with terms referring to the receiver as a part in the production of meaning. The success and "true" sense of illustration (the second quote above) is judged after how well it "interpreted something to the reader." Its truthfulness is not in the first place measured against different stages in the line of production (conventionally taken as the author's conception followed by an illustrator's interpretation in drawing), but with recourse to the receiver as interpreter-at

\footnotetext{
19 Blackburn, Art of Illustration, I 8-39, the concept is termed on p. 26.

20 Blackburn, Art of Illustration, 26-27.

${ }_{21}$ Blackburn, Art of Illustration, 29.

22 Blackburn, Art of Illustration, 34-36.
} 
the same time as the first demand adheres to the well-known paradigm of meaning where the textual source is equivalent to authorial intentions. Therefore it is noteworthy that the turn to the receiver is also present and given a determining role in Walter Crane's Of the Decorative Illustration of Books Old and New. For example in the passage below, which is preceded by a reference to the evolutionary theory of Herbert Spencer and explicitly regards the development of writing. But notably, it ends by referring to a generalized experience of book illustrations. Like in Blackburn, the speaking voice is in the concluding clause external. It is not the voice of the receiver in the form of an I-speaker that comes forth, but rather attention to the receiver as a factor in meaning production.

We know that the letters of our alphabet were once pictures, symbols, or abstract signs of entities and actions, and grew more and more abstract until they became arbitrary marks— the familiar characters that we know. Letters formed into words; words increased and multiplied with ideas and their interchange; ideas and words growing more and more abstract until the point is reached when the jaded intellect would fain return again to picturewriting, and welcomes the decorator and the illustrator to relieve the desert wastes of words marshalled in interminable columns on the printed page. ${ }^{23}$

The object spoken about seamlessly changes from an abstracted history of production or the order in which the different types of signs have evolved, to a statement on the experience of reading and viewing them, which cannot but make claims to an extended present tense. This generalized reader/viewer is furthermore granted freedom of interpretation. The reader/viewer may or may not interpret the illustrations in the light of the page's "interminable columns":

In the journey through a book it is pleasant to reach the oasis of a picture or an ornament, to sit awhile under the palms, to let our thoughts unburdened stray, to drink of other intellectual waters,

${ }_{23}$ Crane, Decorative Illustration, 5-6. 
and to see the ideas we have been pursuing, perchance, reflected in them. Thus we end as we begin, with images. ${ }^{24}$

Both the turn to the receiver and Crane's oasis metaphor entail a view on the relationship between illustration and text as flexible. The picture is recognized as possibly deviating from the "ideas pursued," which is however a deviation that also holds for the latter. As in Blackburn, ideas are referred to as derivative entities that are possibly not grasped in their written form. And even though this quote, like the rest of the text, makes use of recurring contrasts between the pictorial and the other textual medium, they are also recognized as alike. The mind's experience of illustrations is, like reading, an intellectual activity (cf. "other intellectual waters"), although more open-ended in the sense of being the object of a generalized mind that "perchance" lets them reflect the text. The meeting with the illustration is further proposed as a necessary pause that compensates for the exhaustion of the "interminable columns," by the visualization of it as an oasis with vegetation and water in the middle of a barren land. If this, on the one hand, could be understood as a plain case of a series of dichotomies, where the image (illustration, ornament) is placed on the side of fertility, oasis, and seeing, and the words on the side of desert, chase after absent ideas, and reading, it is also plain that seeing the illustration is accounted for as alike reading in the sense of being something both sensory and cognitive, which thus indicates a model that is not mutually exclusive. ${ }^{25}$ From the

${ }_{24}$ Crane, Decorative Illustration, 6.

25 This is comparable to the way J. Hillis Miller, in his more recent theory of illustration, on the one hand explores the differences between textual and pictorial media and between the meaning and materiality of the sign in any media, and, on the other, still acknowledges the bridge between media that brackets the differences: "After all, both text and image are something seen with the eyes and made sense of as a sign." Also the semiotic perspective on the continuity between media recalls the texts treated of here. Although the accounts of Crane, Blackburn, and Hillis Miller do not share the same category of sign (which is based on different conceptions of what the sign ultimately refers to), they all give expression to the idea that the point of coherence in textual and pictorial media is the meaning productive mediation of the receiver. Cf. J. Hillis Miller, Illustration (London: Reaktion Books, I992), 73. 
acknowledgement of the receiver thus follows the notion that the interpretation of the illustration may or may not be bound by the text. And in extension, this view also entails the recognition of the illustration as a possible starting point for other ideas than those expressed in writing, which is historiographically important exactly for the reason that it is the order of production that conventionally has been embraced in illustration studies and converted into a model of analysis. ${ }^{26}$ Put differently, the order of production is a model of meaning production partly rejected by the texts of Blackburn and Crane.

So far, I have demonstrated that the modern concept of illustration, represented by the quoted texts, refers to elements of the conventional concept, but is completely different from it. It is better characterized as thoroughly marked by the ambivalence of conflicting and intersecting propositions in the same texts. I have, on the one hand, pointed to a hierarchical organization where the illustration is taking the place of a passive follower, and, on the other, a notion of illustration as a necessary and compensatory healer of deficiencies in writing. And more, on the one hand, a correspondence with the paradigm of authorial intentions as the parameter of meaning, and, on the other, a privileging of the receiver as interpreter. The point is not at all to restore any one aspect of the concept of illustration as a historiographic entity, but to stress ambivalence as a pertinent factor of it.

\section{Illustrating Ambivalence and the Ambivalence of Illustration}

The concept of ambivalence that has been derived from the historiographic readings will now serve as a guide for my further analysis. But it does not occupy that position alone. In this section, the concept of new media, or the second aspect of my operational

${ }^{26}$ One exception is the semiotic paradigm represented by, e.g., Hillis Miller in note 25. Otherwise, Bland is an example of using the model of production as the logic by which illustrations with added texts are treated as deviations from illustration proper. Bland, History of Book Illustration, 253, 257. 
definition of illustration, will be especially activated. Some points from previous sections first need to be rehearsed and briefly expanded on.

The conventional concept of illustration can be said to refer to a double separation or a double hierarchy: between text and illustration and between illustration as art and as something else. The latter could certainly be almost anything, but in the particular time and media landscape it amounts to the media-historical divide between art and new media of pictorial reproduction. The second demand in Blackburn's definition of illustration actually seems to presuppose the divide, since it singles out "artistic" as a category of its own. And if this marks a separation within the genre of illustration as "merely" reproductive (material and artistic) or as art, it also corresponds well to the division of content in Blackburn's book, where the chapter on "Elementary Illustration" is separated from the chapter on "Artistic Illustration." In its turn, this divide corresponds to the distinction between "useful" and "aesthetic" drawing in Philip Gilbert Hamerton's at the time wellknown treatise The Graphic Arts (I 882), which is also one of Blackburn's references. ${ }^{27}$ In both texts, the crucial points are that pictorial print media is multipliable and that the genre of illustration was intimately bound to print media in general and the new media of pictorial reproduction in particular. ${ }^{28}$ Hamerton finds reason to deplore the present multiplication of xylography as "an adjunct to journalism" and, together with lithography, blame its "abuse in commerce." ${ }^{29}$ Within the discipline of art history, this (purported) split has lately been researched as a product of the rise of the concept of "original print" and associated with the texts and interests of etcher's organizations and graphic art theorists like Hamerton. ${ }^{30}$ In a broader perspective, it can be thought

${ }^{27}$ Philip Gilbert Hamerton, The Graphic Arts: A Treatise on the Varieties of Drawing, Painting, and Engraving in Comparison with Each Other and with Nature (Boston, I 882), 8-48.

28 See also the definition of illustration in Joseph Pennell, Modern Illustration: Its Methods and Present Conditions (London, I898), I-8.

29 Hamerton, Graphic Arts, xiv.

$3^{\circ}$ Cf. Jan af Burén, Det mångfaldigade originalet: Studier i originalgrafikbegreppets uppkomst, teori och användning (PhD diss., Stockholm: 
of as underpinned by the romantic and autonomous concept of art or the notion informing the doubly derogative sense of the new media of illustration as "an adjunct to journalism": with a reproduced materiality, in the service of a particular textual source, and lacking original artistic intention. But for the reasons discussed above, my objective is not to search for further signs of the separation that already has the status of convention, but rather to study it in the light of ambivalence, as neither fixed nor especially pure. To that end I now turn to the front page of $\mathrm{Ny}$ Illustrerad Tidning (Figure I).

Pictured on the front page is a model of continuity rather than divide between media that have been categorized either as art or as reproductive. In other words, it is a model transgressing the boundaries of the (assumed) split within the genre of illustration. The front page shows a montage of reproduced works by the German artist Gustav Richter. Its title at the bottom of the page is non-medium specific; it mentions "Some pictures by [...]." Importantly, the "pictures" are not named paintings, since it is lithographs, a medium on a paper surface that was closely associated with colour reproductions of oil paintings. Seven lithographs are shown mounted on top of each other and pinned to a wooden board. This is a description of the motif suggested by the title, and it involves the respective medium of oil painting (by allusion: the motifs in the motif are attached to an idea of a painted original) and lithography (by depiction). The latter is, however, not the sole media of pictorial reproduction re/presented on the front page. The pictorial surface presents-not represents-the medium of xylography, characterized by its overall parallel strokes and cross-hatchings and still in the $\mathrm{I} 88 \mathrm{os}$ associated with the illustrations of the popular press. The reference to lithography is therefore doubled: it is made both by the imitation of its tonal style in xylographic strokes and cross-hatchings, and by the depiction of the nailed up prints. Another manifest sign of pictorial reproduction is the inscription on the pictorial surface in the left corner-on the

Carlssons, I992); Elizabeth Helsinger et al., The "Writing" of Modern Life: The Etching Revival in France, Britain, and the U.S., I850-I940, exh. cat., Smart Museum of Art (Chicago: University of Chicago, 2008). 


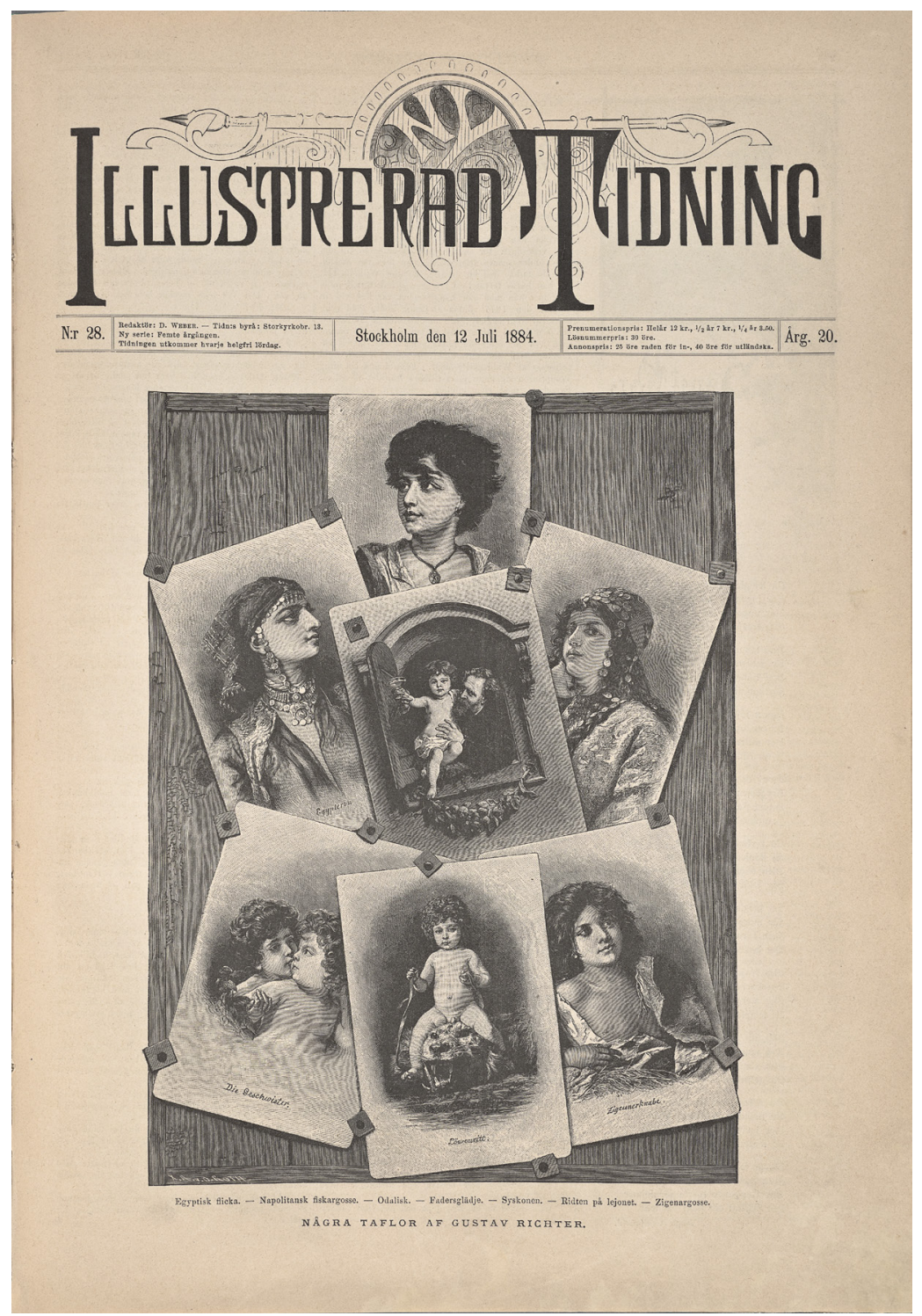

Figure 1. Front page of Ny Illustrerad Tidning, I 884. Reproduction: National Library of Sweden/Kungliga biblioteket, Stockholm. License: CC-BY-NC-ND. 
surface as distinct from in the motif (as the German titles beneath the motifs on the prints represented). It signifies reproduction not so much because of what it says (although "XA" means xylographic atelier) but because of the fact that it is reversed, a not unusual accident in production when the marks from one surface were transferred to another. ${ }^{3 \text { I }}$ But here, it is noteworthy not as a reference to the practice of production but as a sign of reversibility itself, which could alternately be called not static, changeable, transposable, unfixed. And there is still another contemporary media of pictorial reproduction referred to by the montage manner of the front page, namely photography. This reference hence builds on the formal organization of the motif, and parallels the practice of mounting photographs into albums in similar arrangements. ${ }^{32}$

And more, to this assemblage of media, the illustration also adds itself. By the xylographic surface, the genre of illustration is alluded to as the culturally defined product of xylography in journalistic print media, which is the same connotative relationship as that between the depicted lithographic prints and the medium of painting. Together with the article inside the magazine, to which the picture as an illustration is conventionally expected to refer, the picture on the front page presents the combined mediality of the genre. The material presence of picture and text as a pertinent feature of illustration could be thought of as so obvious that it does not at all provide a source of attention. But then the point of the overall exposure of media would be missed. In being framed by the media genres of lithography, xylography, painting, and photography, the combined mediality of the illustration is enhanced precisely as a presence of media.

The traditionally honourable medium of painting is then, with Mitchell's expression, "nested" within the illustration's continuous assemblage of new media of pictorial reproduction, including

${ }^{31}$ About reversals in the printing process, see Antony Griffiths, The Print Before Photography: An Introduction to European Printmaking I550-I 820 (London: The British Museum Press, 20I6), 35-38.

${ }^{32}$ For illustrations, see Anna Dahlgren, Ett medium för visuell bildning: Kulturhistoriska perspektiv på fotoalbum I850-I950 (Stockholm: Makadam, 2013), 96, I05. 
itself as a new and combined medium. ${ }^{33}$ In this, the illustration on the front page and the article inside the magazine both conjoins and diverts. The latter introduces the twice "reproduced" motifs on the lithographic prints (named "Gipsy boy," "Neapolitan fisher boy" and so on) as the art of the painter and his most popular idealizing subjects, which are contextualized by an account of their reception and the painter's biography. The theme of reproduction is not the overall theme of the article, even though it typically begins by commenting on the wide circulation of Richter's prints, "one sees them in reproduction everywhere." ${ }_{34}$ Both article and front page can thus be said to conjoin in the reference to the medium of painting, although with different angles. The article points to the art of the painter and the illustration to the medium of painting. They also make use of different means: the article narrates the story of the artist's life and reception whereas the illustration represents painting as reproduced in lithography. The emphasis on painting is further doubled by another pictorial reference to the same medium. The first-order motif of the wooden board is reminiscent of a particular trompe l'œil-genre of illusory depictions of wooden wall boards with an assemblage of pinned-up letters, drawings, prints, booklets, and other pieces of paper, a genre practiced from the seventeenth through the nineteenth centuries. ${ }^{35}$ Painting, with its art-historical status as an "auratic" non-reproductive medium, is in various ways nested within the combined media of the illustration, which hence actualizes itself as a media genre in relation to painting, and further shows painting as contained within lithography, moulded by a xylographic surface, and placed aside photography. ${ }^{36}$

This exposure of media (materially present in combination and by the surface, represented by the motif, imitated in style, alluded

33 Mitchell, Picture Theory, 48, 56; Mitchell, Image Science, I3 I-I 32.

34 “Till Gustav Richters taflor," Ny Illustrerad Tidning, no. 28 (I 884): 237.

35 For illustrations, see Lura ögat: Fem seklers bländverk, ed. Karin Sidén, exh. cat., (Stockholm: Nationalmuseum, 2008), 20-30.

${ }^{36}$ For the concept of “aura," see Walter Benjamin's classical essay "The Work of Art in the Age of Mechanical Reproduction," in Illuminations, ed. Hannah Arendt, trans. Harry Zohn (New York: Schocken Books, I968), 2I 7-25I. 
to by organization), makes the illustration move beyond the content of the article. It does not so much illustrate the work of the painter as the assemblage of new media of pictorial reproduction placed in a continuous relation to the art of painting and to the new and combined media of the genre of illustration itself. In sum, the media involved in and on the front page are exposed by an internal series of pointing and emphasizing: the inscription on the surface enhances its status as xylographic reproduction, which in its turn points to the genre of illustration, the montage manner doubles photographic practices with a genre of painting, painting further recurs in the idea of the originals to the motifs on the lithographs depicted, and the lithographic media is emphasized by the mimicked style, except by being part of the first-order motif. ${ }^{37}$

The continuous model exposed by the illustration importantly opposes the historiographic divide between illustration as art and as pictorial reproduction (of textual and/or artistic sources). More precisely, I understand continuity as the semantic outcome produced by the illustration's pictorial and textual parts. When this outcome is turned to face the idea of a divide, it not only opposes it, but in that very opposition makes the latter more uncertain. The illustration on the front page then follows the pattern of ambivalence of intersecting conceptual propositions studied in the previous section. In that sense it further underlines the modern concept of illustration as an only provisional entity or an unstable set of related but incoherent notions.

37 The differences between the orders of re/presentation indicated in the paragraphs above correspond to Bolter and Grusin's broad distinction between "immediacy" and "hypermediacy" or the cooperative forces of remediation, that captures, on the one hand, the perception of and immersion in representational content and erasure of media (seeing lithography and painting represented), and, on the other, enhancement of media by making multiple acts of mediation perceptible (the xylographic mimicking of the lithographic tonal style, the reversed signature, the organization or the montage manner). This means that Bolter and Grusin's terms are employed here to theoretically inform the concept of new media drawn from Gitelman (note I I), but they are, because of lack of precision, not made operative in the details of the analysis. Cf. Bolter and Grusin, Remediation, 2I-44, 54-5 5, 70-7I. 
But besides accommodating the instability of the modern concept of illustration as a historiographic entity, the illustration also exposes another kind of ambivalence, analytically building on properties that are not so much derived from preconceived words as from the illustration itself and relating to metalanguage sideways. The front page gives rise to questions about media and genre borders and their transgression partly provoked by my, at first, naïve reference to it as a front page-which is not completely wrong. It is the first page of the number, complete with letterhead and cover illustration. But the untheorized referring to it as a given unit actually entails the problem of the illustration's own borders. To simplify a bit, the intuitive delimitation of the illustration as a picture is the thin outline surrounding the wooden board (which is nonetheless broken by the outbreaking drawing pins), whereas the intuitive delimitation of the illustration in the combined media sense, is the picture placed in relation to the title beneath it and the article further on. What the illustration in its combined media sense does not include is the elements belonging to the front page, like the letterhead, the ornamental motif of shield and spear or the white margins. These elements thus have in common that they are conventionally excluded from the illustration's physical extension on the page and from the textual units it is conventionally expected to illustrate, which is an exclusion shared by a particular quality of the pictorial surface that can be called its "graphicness" or its many parallel and crossed strokes. It is this particular quality that gives rise to the questions of border transgression, once it is recognized that it is a quality the pictorial surface have in common with some elements on the page, or elements within the illustration's immediate proximity but without its conventional borders: the horizontal bar that runs beneath the letterhead and the vertical strokes intersecting the ornament behind the accentuated name of the magazine.

The communality between the pictorial surface, the horizontal bar, and the vertical strokes, however, hinges upon a restricted sense of graphicness as material forms that are neither textual nor pictorial. The graphic qualities that now have been pointed out are not pictorial in the same figurative way as depictions of things (like lithographs and drawing pins) or figures (like the 
second-order motif of the "Egyptian girl") or scenery (like the architectural frame in the middle print or the river shore in the lower). Neither are they textual in the material sense of being shaped like letters or narrative in the same straightforward way as the subject entitled "Father's joy" is pictorialized by the man holding/showing a child and helping it to raise a cup in a gesture of celebration. Consequently, the strokes of the pictorial surface should be distinguished from, for instance, the similar strokes of the wooden board, or strokes that are ceasing to be graphic the moment they are recognized and accounted for as "grainings in wood"-which is almost automatically done. The graphic elements of the pictorial surface are not as easily accountable for, but still not beyond conceptualization. The latter is actually achieved already by calling them "traces after graphic tools" or "graphic qualities." ${ }^{8}$ Of course, it could be objected that the bar and the traces after graphic tools are not in all aspects similar cases. The former organizes the textual units within it by grouping, dividing, and outlining, and are thereby connected to the qualities Johanna Drucker more broadly calls "information graphics," 39 while the latter makes out the overall pictorial surface and gives texture to depicted figures, things, etc. The vertical strokes behind the letterhead is still another case of filling in space. One reason to separate this graphic quality from more textual and pictorial counterparts and make it into a category of its own is, however, to make a point of its in-betweenness. While the combined-media approach targets text and picture, the graphic elements are neither the one nor the other. And from the conventional point of view, they are not recognized as the essential, meaning-producing elements of the

${ }^{38} \mathrm{I}$ am here distancing my terminology from James Elkins's “graphic marks." Like me, Elkins recognizes the traces after tools as analytical units but refuses them sign function by calling them "marks," in an argument completely opposed to the project I am committed to. Elkins's critical agenda is to estrange pictures as non-textual, whereas mine is to verbalize and communicate the semantic dimension also of graphic qualities. James Elkins, On Pictures and the Words That Fail Them (Cambridge: Cambridge University Press, I998), 3-46, 73, 213, 2 I 5.

39 Johanna Drucker, Graphesis: Visual Forms of Knowledge Production (Cambridge: Harvard University Press, 20I4), 64-I37. 
genre, as long as the idea of a textual counterpart corresponding to narrative parts of motifs serves as the parameter for what is essential to illustration's meaning production.

Now, the graphicness of both surface and page invites a metalanguage that accounts for their transgressive status. This is to be found in Derrida's concept of "parergon," which terms the frame (parergon) of a work (ergon) and conceptualizes it as the double work of de/composing borders. The frame is recognized as the dual device that aligns the inside with the outside, while it also cuts off. Derrida characterizes it as an intervening third, which is both exterior and interior to the object framed. The frame is exterior in being, from the point of view of the essential qualities of the work, imposed from without. But when it is brought onto the work, it is not only annexed to it but is also made operative on its inside. $4^{\circ}$ When graphic qualities are now recognized as parergonal qualities, their border transgression can be qualified in two ways. Firstly, in being conceptualized as the parergonal framework from which to consider combined mediality. In their very difference, graphic qualities make the distinctions between textual and pictorial media both visible and transgressed. This idea builds on the simple fact that to speak about graphic qualities as different already presupposes the definition of illustration as a combination of textual and pictorial media. The point, however, is that when graphic qualities by differing point to the notion of textual and pictorial distinctness, they in the same move transgress the concept of combined mediality, as being omitted from the combination, but still "there," in the illustration. This is the parergonal duality of a framework that is both interior and exterior. Graphic qualities have been brought to, imposed upon, the illustration as a combined medium, and made operative on its

$4^{\circ}$ Jacques Derrida, The Truth in Painting, trans. Geoff Bennington and Ian McLeod (Chicago: University of Chicago Press, I987 [1978]), 37-82, esp. 54-56, 69-74. In the discussion here, "parergon" is used as a concept evoked by and therefore also guided by the illustration, which has made me leave out considerations of the supplementary function Derrida assigns to it. My pictorial example warrants questions of borders and transgressions, but not necessarily questions of supplementarity. Cf. Derrida, Truth in Painting, 56, 57, 59-60, 64, 71, 78-79. 
inside when understood as a question of border transgression. Remember "not beyond verbalization" above; graphic qualities are here made to "speak" about how they exceed the constraints of the combined medium. If this first aspect has to do with how the illustration is allowed to give rise to words, to content, the second aspect has to do with the illustration's concrete transgression of its conventional extension on the page. The graphicness of the pictorial surface mimics the graphicness of the horizontal bar and the vertical strokes of the page. Their graphic qualities have different material realizations but are nonetheless aligned in their in-between status and in that respect traverses the cut of the combined-media approach. In other words, what has now been attended to via the parergonality of the graphic surface is a parallel case of the ambivalence of intersecting models discussed above.

To summarize what has happened in the analysis in this section, there is both seriality and a change of positions involved. Initially, the ambivalence of the modern concept of illustration suggested by the historiographic readings pointed out the direction of analysis, paired with the attention to the surface suggested by the concept of new media. These two guides were in their turn conditioned by my approach to the illustration as self-referential. Also initially, and derived from the concept of new media, came the stress on the surface's visibility. I made a point of the transgression of the historiographic divide between art (represented by painting) and illustration as a new medium of pictorial reproduction (represented by the exposure of the whole assemblage of media genres) that, taken as a "text" or something I textualized by verbalizing it as a conceptual entity (a model of continuity), stresses the conceptual unfixedness in the first section and throws equivocal light on the (presumed) divide. Then, the (xylo)graphic quality of the surface, initially pointed out by the concept of new media, needed further attention as graphic. The surface did not, so to speak, completely fit the frame. With recourse to the concept of parergon I pointed to graphicness as a hybrid between textual and pictorial media and a bridge between pictorial surface and page that intersects the conventional borders of the genre of illustration. From this it can be said that the concept of ambivalence has indeed 
been illustrated by the front page, but that the analytical process of making it illustrate has included an oscillation between a concept that is the outcome of historiographic readings, reliance on convention, and concepts drawn from media studies and philosophy, or an oscillation where the illustration is both used as an object made to accommodate preconceived words and allowed to give rise to further adjustments of analysis.

\section{Conclusion}

One of the study's preconditions was to recognize that the two basic positions of illustrated and illustrating need not be tied to any particular type of object, whether pictorial or textual. With this in mind, "basic positions" are more properly called functions than "positions," since the latter have unhappy associations to something stable and fixed once and for all. The entity that is allowed to function as either illustrated or illustrating is exchangeable, the functions can be activated both simultaneously and serially, and the "same" object could in the course of analysis occupy both at different stages.

Thinking illustration as two exchangeable and reversible functions does not propose a passive and in the stronger sense mimetic task for the object that for the moment is illustrating. This has been exemplified by attending to the transmedial processes by which a semantic outcome has been allowed to deviate from its initial shape. Ambivalence was first modelled out in historiographic readings and then adjusted by the confrontation with the front page, used as an illustration of it. The illustration, however, offered both a "new" content to the initial term while still keeping in accordance with it, and an ambivalence of its own as a point from which to further understand the initial concept. It turned ambivalence from an issue of intersecting conceptual models to a graphic issue about its own (imposed) borders or "frame-up" as illustration, in the serial course of the study.

Although my study in a less-specified sense has dealt with one illustration, it must be stressed that it is nonetheless a composite object also in other ways than is suggested by its semantic 
equivocality and media combination. Additionally, it has been compartmentalized into the parts of surface, (parts of) motif(s), graphic qualities, organization, and further into different levels of re/presentation. These parts were dealt with in the same, more or less simultaneous, step and were used to counter the serially elaborated combination of concepts (new media and ambivalence from the start and subsequently parergon, when the front page was already understood in terms of the former concepts). In other words, neither the "object" employed for the (reversible) purpose of illustrating, nor the "object" employed to be illustrated is one-dimensional.

All in all, the operational definition of illustration that preconditions the study has been slightly elaborated. I started by pointing to the relationship between combined mediality and metalanguage and the reversibility of the basic positions. I have ended up with understanding the latter as two analytical functions occupied by exchangeable and reversible composite objects.

\section{References}

Bal, Mieke. Reading "Rembrandt": Beyond the Word-Image Opposition. Cambridge: Cambridge University Press, I99I.

Bal, Mieke. Travelling Concepts in the Humanities: A Rough Guide. Toronto: University of Toronto Press, 2002.

Barthes, Roland. Image Music Text. Translated by Stephen Heat. London: Fontana, I977.

Benjamin, Walter. "The Work of Art in the Age of Mechanical Reproduction.” In Illuminations. Edited by Hannah Arendt, translated by Harry Zohn, 27I-25I. New York: Schocken Books, I968.

Blackburn, Henry. The Art of Illustration. London, I 896 [I894].

Bland, David. A History of Book Illustration: The Illuminated Manuscript and the Printed Book. London: Faber and Faber Limited, I958.

Bolter, Jay David, and Richard Grusin. Remediation: Understanding New Media. Cambridge: MIT Press, I999. 
Burén, Jan af. Det mångfaldigade originalet: Studier i originalgrafikbegreppets uppkomst, teori och användning. PhD diss. Stockholm: Carlssons, I992.

Crane, Walter. Of the Decorative Illustration of Books Old and New. London, I 896.

Curtis, Gerard. Visual Words: Art and the Material Book in Victorian England. Aldershot: Ashgate, 2002.

Dahlgren, Anna. Ett medium för visuell bildning: Kulturhistoriska perspektiv på fotoalbum I850-I950. Stockholm: Makadam, 20I3.

Derrida, Jacques. Of Grammatology. Translated by Gayatri Chakravorty Spivak. Baltimore: Johns Hopkins University Press, I 997 [1967].

Derrida, Jacques. The Truth in Painting. Translated by Geoff Bennington and Ian McLeod. Chicago: University of Chicago Press, I987 [1978].

Drucker, Johanna. Graphesis: Visual Forms of Knowledge Production. Cambridge: Harvard University Press, 2014.

"Editorial." Journal of Illustration Studies (December 2007). Accessed August I 8, 20I 5. http://jois.uia.no/articles.php?article $=42$.

Elkins, James. On Pictures and the Words That Fail Them. Cambridge: Cambridge University Press, 1998.

Elleström, Lars. Media Transformation: The Transfer of Media Characteristics Among Media. Basingstoke: Palgrave Macmillan, $20 I 4$.

Frankel, Nicholas. Masking the Text: Essays on Literature \& Mediation in the I890s. High Wycombe: The Rivendale Press, 2009.

Gitelman, Lisa. Always Already New: Media, History, and the Data of Culture. Cambridge: MIT Press, 2006.

Gitelman, Lisa, and Geoffrey B. Pingree, eds. New Media, I740-I9I 5. Cambridge: MIT Press, 2003.

Griffiths, Antony. The Print Before Photography: An Introduction to European Printmaking I550-I820. London: The British Museum Press, 2016.

Hamerton, Philip Gilbert. The Graphic Arts: A Treatise on the Varieties of Drawing, Painting, and Engraving in Comparison with Each Other and with Nature. Boston, I 882. 
Helsinger, Elizabeth, Martha Tedeschi, Anna Arnar, Allison Morehead, Peyton Skipwith and Erin Nerstad. The "Writing" of Modern Life: The Etching Revival in France, Britain, and the U.S., I850-I940. Exhibition catalogue, Smart Museum of Art. Chicago: University of Chicago, 2008.

Hodnett, Edward. Image \& Text: Studies in the Illustration of English Literature. London: Scolar Press, 1982.

Janzen Kooistra, Lorraine. Poetry, Pictures, and Popular Publishing: The Illustrated Gift Book and Victorian Visual Culture I $855-1875$. Athens: Ohio University Press, 201 I.

Korda, Andrea. Printing and Painting the News in Victorian London: The Graphic and Social Realism. Burlington: Ashgate, 2015.

Lund, Hans. Mötesplatser: Ord och bild $i$ samverkan. Lund: Intermedia Studies Press, 20I3.

Lura ögat: Fem seklers bländverk. Edited by Karin Sidén. Exhibition catalogue, Nationalmuseum. Stockholm: Nationalmuseum, 2008.

Miller, Hillis J. Illustration. London: Reaktion Books, I992.

Mitchell, W. J. T. Image Science: Iconology, Visual Culture, and Media Aesthetics. Chicago: University of Chicago Press, 2015.

Mitchell, W. J. T. Picture Theory: Essays on Verbal and Visual Representation. Chicago: University of Chicago Press, I994.

Pennell, Joseph. Modern Illustration: Its Methods and Present Conditions. London, I 898.

Rajewsky, Irina O. "Intermediality, Intertextuality, and Remediation: A Literary Perspective on Intermediality." Intermediality: History and Theory of the Arts, Literature and Technologies, no. 6 (2005): 43-64.

Schapiro, Meyer. Words and Pictures: On the Literal and the Symbolic in the Illustration of a Text. The Hague: De Gruyer Mouton, I973.

“Till Gustav Richters taflor." Ny Illustrerad Tidning, no. 28 (г 884): 237-238.

Yousif, Keri. Balzac, Grandville, and the Rise of Book Illustration. Burlington: Ashgate, $20 \mathrm{I} 2$. 
